\title{
South Africa: Youth centers: A costly way to provide reproductive health services
}

Frontiers in Reproductive Health

Follow this and additional works at: https://knowledgecommons.popcouncil.org/departments_sbsr-rh

Part of the Demography, Population, and Ecology Commons, Family, Life Course, and Society Commons, International Public Health Commons, Maternal and Child Health Commons, and the Medicine and Health Commons

How does access to this work benefit you? Let us know!

\section{Recommended Citation}

"South Africa: Youth centers: A costly way to provide reproductive health services," FRONTIERS OR Summary no. 66. Washington, DC: Population Council, 2007. 


\section{South Africa Youth}

OR Summary 66

\section{Youth Centers: A Costly Way to Provide Reproductive Health Services}

Economic analysis showed that the youth center model is a costly way of attracting young people to seek reproductive health information and services. Managers should identify their goals in providing multipurpose youth centers and identify the best models relative to these goals.

\section{Background}

Numerous reproductive health programs sponsor youth centers, which provide recreation and job skill training as a means of attracting young people to obtain reproductive health services or information. However, the productivity, cost, and cost-effectiveness of this approach are not clearly documented.

In 2000 with the Reproductive Health and HIV Research Unit of Witwatersrand University, FRONTIERS conducted a cost analysis as part of a larger study on the effectiveness of three different youth center models in South Africa (see Erulkar et al 2001). The cost study focused on eight of the 12 centers included in the larger study, chosen to be representative of each model. All of the selected centers offered clinical services; seven also offered reproductive health information or life skills training; and three also offered vocational and recreational services. The cost study examined the total costs for each center, as well as the cost of both a clinic visit and a reproductive health visit.

The total cost for each center included the cost of all resources (labor, capital such as buildings, and supplies) required to produce each type of service offered. For the clinics that offered vocational and recreational services, the costs of clinical and reproductive health visits were calculated under three scenarios: 1) the cost of job skills and recreation programs were included, as these programs are primarily meant to facilitate youth to meet with a peer educator or a nurse for reproductive health services; 2) half of the cost of the programs were included, as they are meant to increase youth development and job skills and to attract youth to seek clinical and reproductive health services; and 3) the costs of the programs were excluded, as these programs are primarily seen as increasing youth development and job skills.

\section{Findings}

Many inter-related factors affected costs, including the type and variety of programs offered, the number of staff, whether the staff also provided services to older women, size of the buildings, the amount of supplies used, and the volume of clients for each service.

- Annual overall costs for each center varied widely, ranging from a high of about US $\$ 80,000$ per year to a low of about $\$ 12,000$ (see Figure 1). At three centers, the costs of the recreation and vocational programs are at least as high as the cost of their clinical programs.

Figure 1. Youth center costs by program

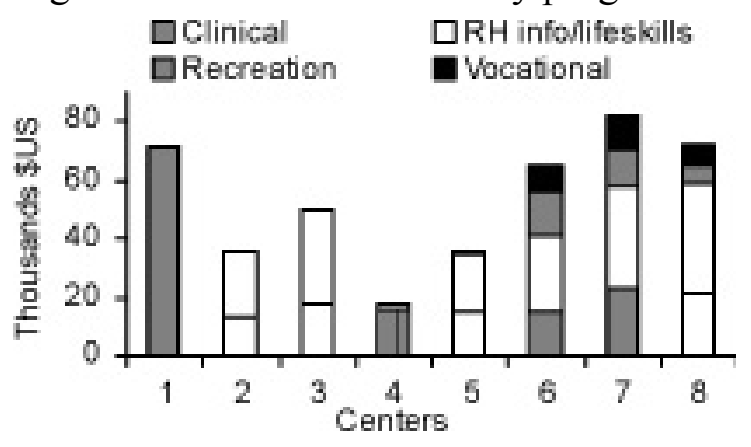

Zirontiers 
- Programs for reproductive health information and life skills education are generally more costly than clinical programs. Reproductive health and life skills programs accounted for the highest percentage of costs in six of the eight centers.

- Use of the centers - another factor in the cost of services-varied considerably from a high of nearly 450 weekly visits to less than 50 visits per week. Young people's reasons for visiting also varied (see Figure 2).

Figure 2. Number and type of weekly visits for each center from sign-out register

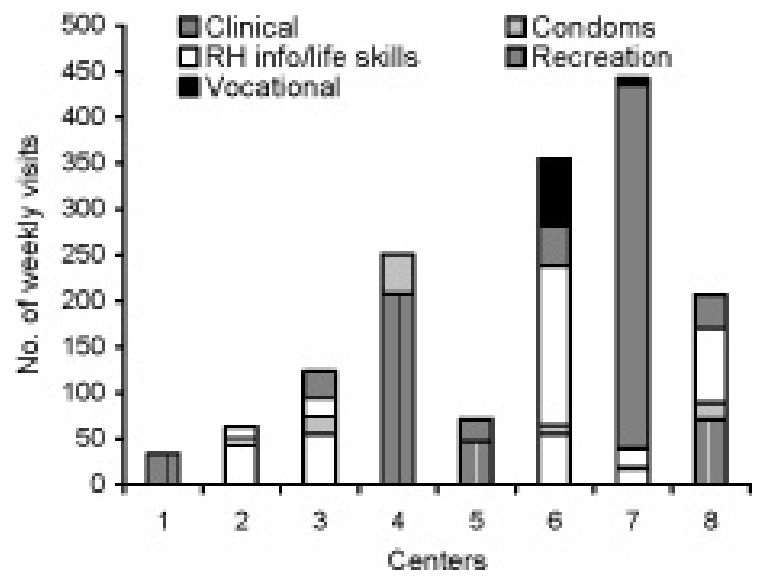

- The unit cost of service varied widely: a clinic visit cost between $\$ 4$ and $\$ 10$, while the cost per educational or life skills visit varied between about $\$ 1.50$ and $\$ 18$. The cost for a visit to meet with a peer educator varies across centers primarily because the demand for this service varies greatly - from over 9,000 visits annually to around 1,000 visits.

- The cost per clinical visit was higher in centers that also offered job skills and recreation programs, even when the cost of the programs was not included in the cost of visits. When the costs are included, with the common assumption that the programs attract youth to seek services, the costs of a clinic visit increased by over 40 percent. At one center with large recreation and job skills programs, the cost of a clinical visit is over $\$ 11$. Without these programs, thus excluding the costs of these services in the cost of a clinical visit, the cost would be under $\$ 8$.

- Labor costs for clinical visits varied considerably, from over $\$ 4$ to less than $\$ 2$ per clinical visit. This variation was partly due to variations in client volume, which averaged from seven to 17 patients per day. However, much of the clinical cost was due to indirect labor costs, or costs for administrative work and other activities not related to seeing clients. In no clinic was the proportion of labor costs allocated to meeting clients greater than 50 percent.

\section{Policy Implications}

- Since programs for recreation and job skills increase total center costs but do not increase the number of youth that visit clinics or meet with a peer educator, these programs are difficult to justify on the basis of their contribution to reproductive health. However, if managers view youth centers as a means of reaching other ends - such as meeting adolescents' need for recreation and job training - then the cost of these youth centers should be compared with those of programs with similar objectives.

- Given the high costs of peer education visits as compared to clinic visits, information is needed on the content of those visits as well as on ways to reduce costs. The performance of peer educators is highly variable, and more information is needed on what they accomplish both within and outside the centers.

Source: Janowitz, Barbara et al. 2003. "The costs of programmes at selected youth centres in South Africa," FRONTIERS Report. Washington, DC: Population Council. See also Erulkar, Annabel et al. 2001. "An assessment of youth centres in South Africa." FRONTIERS Final Report. Washington, DC: Population Council. Both available on our website at www.popcouncil.org/frontiers/finalreports.html or by e-mail:frontiers@pcdc.org

This publication is made possible by the generous support of the American people through the United States Agency for International Development (USAID) under the terms of Cooperative Agreement No. HRN-A-00-98-00012-00. The contents are the responsibility of the FRONTIERS Program and do not necessarily reflect the views of USAID or the United States Government. 